\title{
Norsk Arkeologisk Selskap
}

\section{Årsberetning og regnskap 2017}

Den ordinære generalforsamling for år 2017 ble avholdt 5. april $2017 \mathrm{i}$ «Professorboligen», Karl Johansgate 47 i Oslo. Til stede var 46 medlemmer.

Følgende ble protokollert fra generalforsamlingen:

- Preses, Ole Rikard Høisæther, ønsket velkommen til den 80. generalforsamling. Elisabeth Jerkø ble valgt til å undertegne protokollen.

- Årsberetningen og regnskapet var sendt ut sammen med innkallingen til generalforsamlingen. Det var merknad til årsberetningen fra Egil Mikkelsen når det gjaldt omtalen av Vestfoldturen 13. september, man rakk ikke innom gravfeltene på Agnes og Brunla.

- Ole Rikard Høisæther gjennomgikk regnskapet. Det var spørsmål fra salen som gjaldt «annen kortsiktig gjeld» i regnskapet for 2016. Styret sjekker dette, men antar at det omfatter ubetalt gjeld som nå er oppgjort. Det ble også påpekt at avsetningen til Fondet er svært lav, og styret ble anmodet om å øke midlene til Arkeologisk fond.

- Preses viste til revisjonsrapporten, som ble vedtatt av generalforsamlingen med kommentarene over.

\section{Medlemskontingenten}

Styret foreslo samme kontingent for 2018 som for 2017 :

$\mathrm{Kr}$. 400,- for enkeltmedlemmer

Kr. 525,- for ektepar/familiemedlemskap

Kr. 225,- for studenter/skoleelever

Livsvarig medlemskap er 20 ganger kontingenten for enkeltmedlemmer.

Forslaget ble vedtatt. 


\section{Valg av styre}

Ole Rikard Høisæther redegjorde for valgkomiteens forslag til styresammensetning for 2017.
Preses:
Lyder Marstrander

Styremedlemmer: Elin Dalen (gjenvalg 2017 og 2018)

Christian Størmer (gjenvalg 2017 og 2018)

Sonja V. Robøle (ikke på valg)

Ronny Henriksen (ikke på valg)

Leif Dan Birkemoe (ikke på valg)

Per Kristian Skulberg (ny)

Ellen Drage (ny)

Generalsekretær: Frode Iversen (gjenvalg 2017 og 2018)

Revisor: Bjørn Knivsberg (ikke på valg)

Valgkomiteens forslag ble vedtatt.

Valgkomité for 2017: Egil Mikkelsen, Jorun Vandvik Johnsen og Susanna Thommessen (ikke på valg).

Ole Rikard Høisæther takket avtroppende styremedlemmer Lyder Marstrander, som går inn i styret som ny preses, og Elisabeth Farnes for innsatsen.

\section{Foredrag}

Etter generalforsamlingen takket ny preses Lyder Marstrander Ole Rikard Høisæther for innsatsen som preses i Norsk Arkeologisk Selskap. Marstrander presenterte seg selv og glimt fra sin karriere i norsk arkeologi, samt sine tanker om Norsk Arkeologisk Selskap. Det ble videre holdt to foredrag:

Professor Svein Gullbekk, Universitetet i Oslo, holdt foredrag med tittelen: «Penger og kommunikasjon: Religiøs praksis».

Dr Lisbeth Skogstrand, Riksantikvaren, holdt foredrag med tittelen: «Vae victis! Ve de beseirede!».

Etter foredragene ble det servert ost og vin til 45 deltagere.

\section{Turer}

Norsk Arkeologisk Selskap arrangerte tur til Bayern i Tyskland 18.-25. mai 2017. 62 personer deltok på turen. Fagansvarlig for programmet var generalsekretær Frode Iversen. Arrangementsansvarlig og turleder var styremedlem Sonja V. Robøle.

Lørdag 9. september gikk årets høsttur til Mjøsområdet. Turdeltakerne fikk omvisning av utgravingene på Eid, og i Eidsvoll kirke. Etter lunsj på Gjøvik ble det omvisning ved veideristningene på Stein, Tolvsteinsringen og Ringsaker kirke. 
Det var 84 deltagere med på turen. Fagansvarlig for programmet var generalsekretær Frode Iversen. Arrangementsansvarlig og turleder var styremedlem Sonja V. Robøle.

\section{Stiftelsesmiddagen}

Fredag 17. november 2017 ble den femte stiftelsesmiddagen holdt i Det Norske Videnskaps-Akademiets lokaler, Drammensveien 78 i Oslo.

Det ble holdt to foredrag før middagen:

- Dr. Stuart Brookes holdt et foredrag som tok for seg landskapet og arkeologien som vi vil få oppleve på Englandsturen i 2018: «The Archaeology of Wessex»

- Anna Petersén, prosjektleder på den svært spennende utgravingen av Klemenskirken i Trondheim, holdt foredrag med tittelen: «NIKUs kirkeutgraving i Trondheim - fire kirker på samme tuft over vikingtidens kaupang, dateringsunderlag og tolkninger»

Etter foredragene, og informasjonen om vårturen i 2018, ble det servert en treretters middag. Under middagen fikk tidligere preses Lise Tschudi, Christen Aass og Ole Rikard Høisæther hver sin forgylte medlemsnål. Nye medlemmer fikk også utdelt medlemsnål.

\section{Arkeologisk fond - tildelinger 2017}

Til Arkeologisk fond kom det i 2017 inn 5 søknader.

Fondsstyret har bestått av Egil Mikkelsen, Frode Iversen, Lyder Marstrander og Petter B. Molaug.

Fondsstyret besluttet å tildele midler til alle 5 søkere:

Hege Bakke-Alisøy, Arnatveit: 5000 kr. Reisestøtte til feltarbeid i Hellas.

Sigrid Samset Mygland, Bergen: 9000 kr. Støtte til publisering av doktorgradsavhandling. Marie Ødegaard, Oslo: $9000 \mathrm{kr}$. Støtte til publisering av doktorgradsavhandling.

Merete Moe-Henriksen, Trondheim: $5000 \mathrm{kr}$. Støtte til publisering av «Arkeologi og kulturhistorie fra Nordsjøen til Bottenhavet». VitArk 11.

Ingrid Ystgaard, Trondheim: 7000 kr. Støtte til symposium for professor Lars F. Stenvik.

Totalt ble det delt ut kr. 35000 kroner.

\section{Økonomisk situasjon}

Selskapets økonomi er i god orden. Årsregnskapet er lagt frem under forutsetning av fortsatt drift. Årsregnskapet viser et overskudd på kr 162759 kroner, av dette utgjør 81991 kr fondsøkning fra Skagen Global og Holberg Norden. Etter styrets mening gir det fremlagte regnskap et korrekt bilde av selskapets resultat og stilling. Selskapets regnskap føres av deltidsansatt sekretær. 
Det har vært holdt 4 styremøter i løpet av året. På styremøtet 1. juni 2017 besluttet styret å overføre $50000 \mathrm{kr}$ til Arkeologisk fond.

Norsk Arkeologisk Selskap har 537 medlemmer i Norge og i utlandet: 338 enkeltmedlemmer, 81 familiemedlemskap, 14 studenter, 21 livsvarige medlemmer og 2 støttemedlemmer. Det er 89 institusjoner/tidsskriftformidlere som kjøper inn Viking. Det er registrert 19 innmeldinger og 53 utmeldinger. Antallet utmeldinger er ikke et bilde på en medlemsflukt fra Selskapet, men er såpass høyt etter en opprydding i medlemslistene.

\section{Viking}

Viking 2017 ble trykket hos 07 Media AS, Oslo, og sendt til medlemmene i slutten av november.

Redaksjonen har i 2017 bestått av Herdis Hølleland (redaktør), Astrid J. Nyland, Kjetil Loftsgarden, Christian Rødsrud og Astrid Tvedte Kristoffersen (redaksjonssekretær). Sonja Vibeche Robøle og Priscilla Field har lest korrektur. 
Regnskap fra 1.1.2017 - til 31.12.2017

Balanse pr. 31.12.2017

\section{EIENDELER}

DnB NOR 7001.06.00365

75215

DnB NOR 7056.66.15191

579996

DnB NOR 5084.05.24075

10633

Kontanter

400

Skagen Global

319146

Holberg Norden

256762

Forskuddsbetalte kostnader

113216

Lønnsforskudd

$-2073$

Kontingenter og salg av Viking

39685

Sum eiendeler

1392980

\section{GJELD OG EGENKAPITAL}

Skyldige skattetrekk

16937

Skyldig arbeidsgiveravgift

10380

Skyldig AGA ferielønn

1781

Skyldige feriepenger

12495

Arkeologisk Fond 2017:

Pr.1.5.17

99827

- utbetalt i 2017

$-35000$

+ renter 2017

224

65051

Kapitalkonto:

Pr. 31.12.17

1123577

Overskudd

162759

Sum gjeld og egenkapital

1392980 


\section{Resultatregnskap 2017}

\section{Inntekter:}

Medlemskontingent

199973

Etterbetaling fjorårets kontingent

Salg av Viking

107269

Tilpasset arbeidsplass

52135

Overskudd arrangementer

138460

Renteinntekter

3495

Kursoppgang Holberg Norden

36605

Kursoppgang Skagen Global 45387

\section{Sum inntekter}

\section{Utgifter:}

Lønninger

$-195996$

Feriepenger

$-12356$

Fri telefon

$-8202$

Lønn oppgradering hjemmeside

$-17737$

Arbeidsgiveravgift

$-21431$

Arbeidsgiveravgift påløpne feriepenger

$-1781$

Tilbakeført avsatte kostnader

22202

Webhuset (hjemmeside/epost)

$-4247$

Datautstyr/Visma

$-17120$

Trykking Viking

$-115437$

Diverse utgifter Vikingredaksjonen

$-2792$

Tilpasset arbeidsplass

$-17256$

Møter/kurs/husleie/inventar

$-14621$

Kontorrekvisita,porto, telefon

$-8183$

Bankomkostninger

Sum utgifter

-5208
-420165

Årets overskudd

162759 


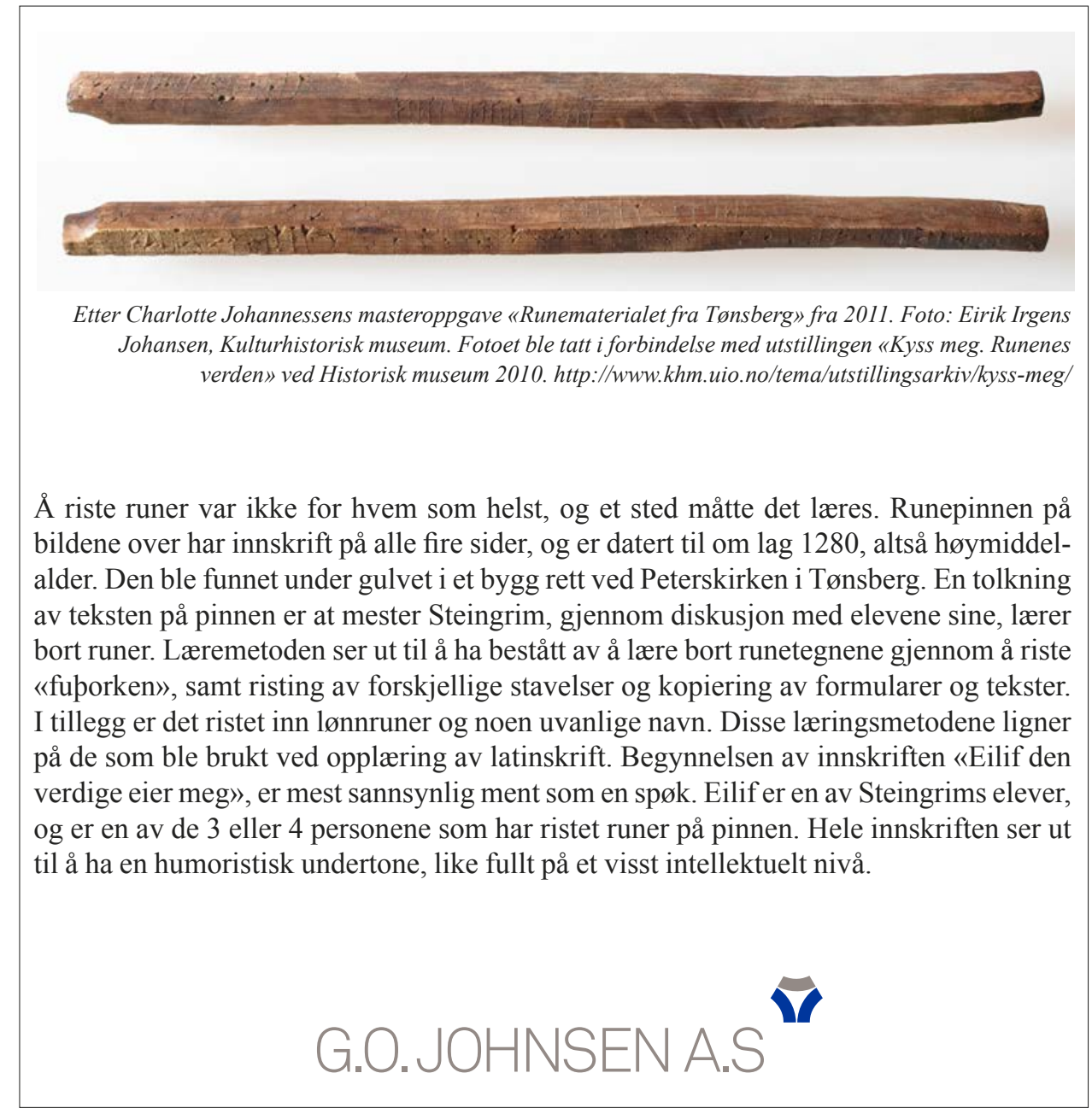




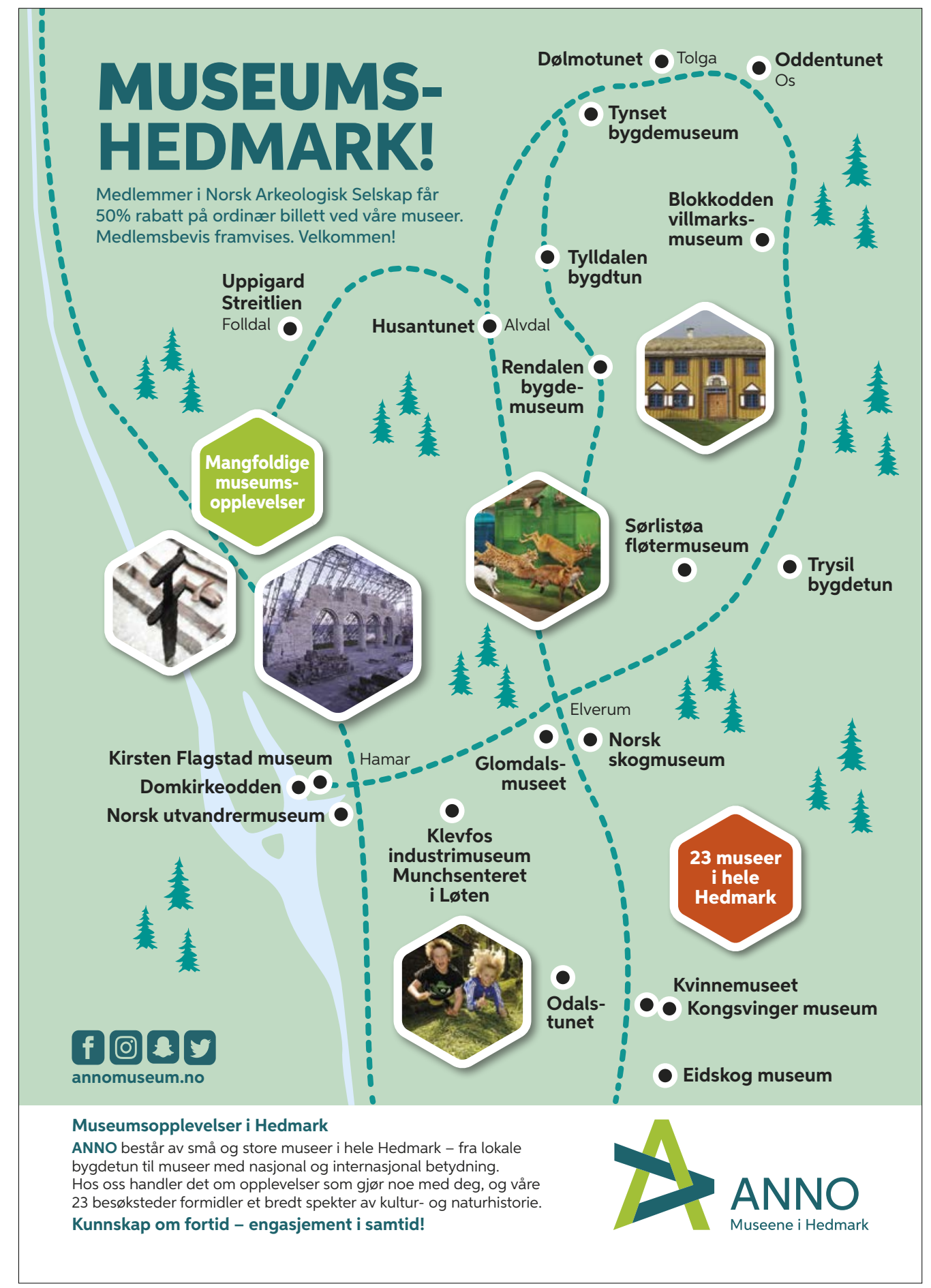




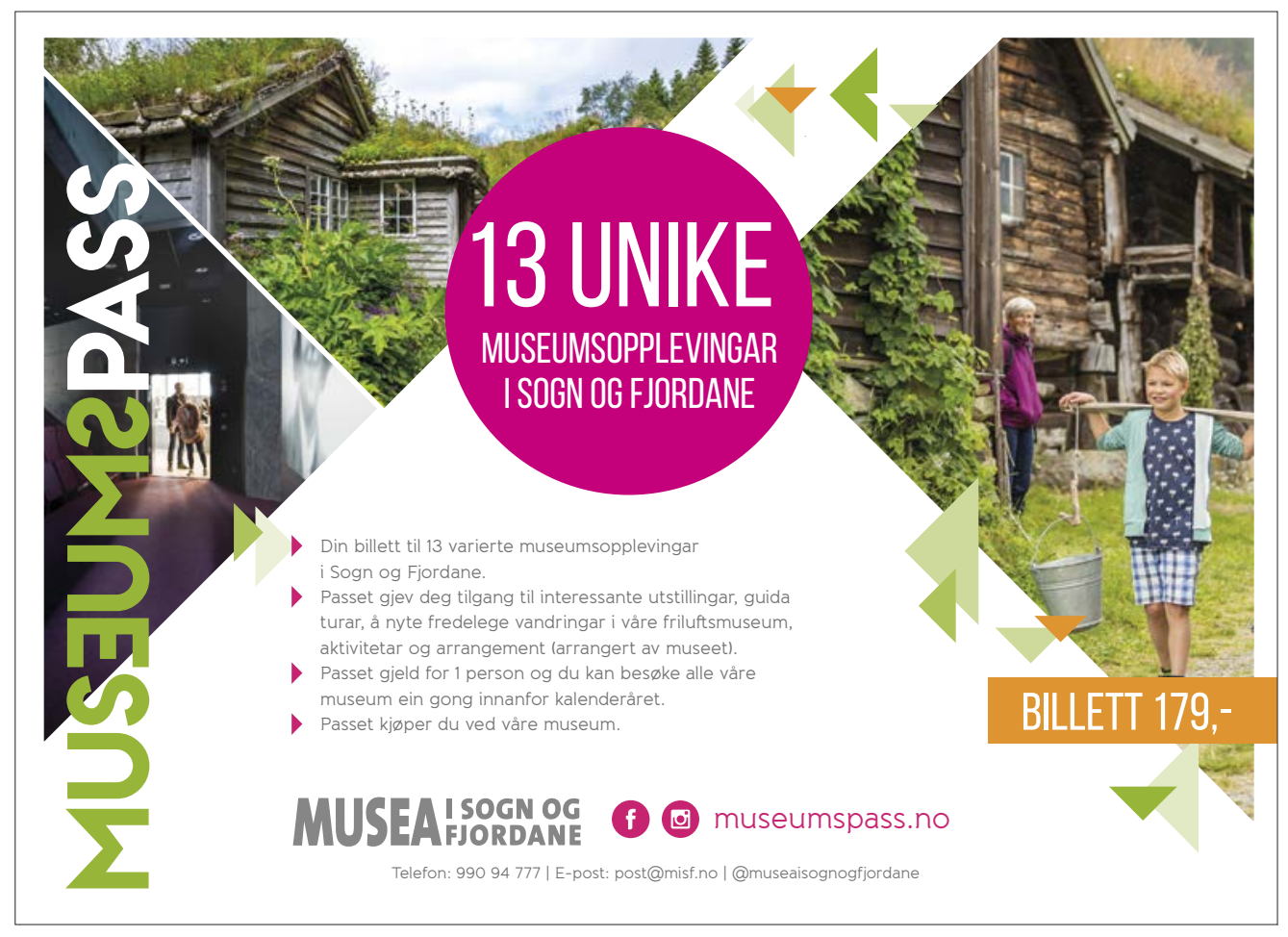




\section{$50 \%$ rabatt}

\section{Medlem av Norsk} Arkeologisk Selskap?

Arkeologisk museum og Jernaldergården tilbyr $50 \%$ rabatt på inngangsbilletten*

${ }^{*}$ Gjelder ved fremvisning av medlemskort i Norsk Arkeologisk Selskap

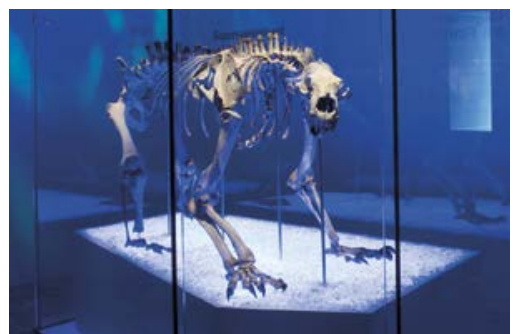

ÅPENT: Tirsdag $11-20$ Onsdag - fredag Lørdag $11-16$ Søndag 10-15 Mandag stengt Våre Tirsdagsforedrag starter 7. oktober kl. 18.30. Auditoriet.

\section{ARKEOIOGISK

